\title{
Laboratory and field studies on the use of artificial mussels as a monitoring tool of platinum exposure in the freshwater environment
}

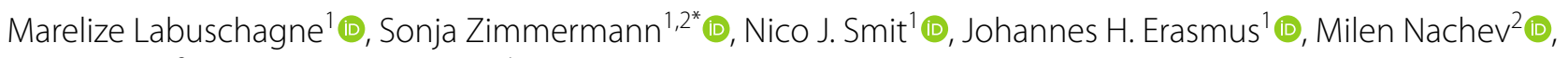
Bernd Sures $^{2}$ (i) and Victor Wepener ${ }^{1}$ (i)

\begin{abstract}
Background: The artificial mussel (AM) is a passive sampling device that was originally developed for monitoring metal concentrations in the marine environment, but is also increasingly used in freshwater environments. The AM consists of a non-permeable Perspex tube, which is closed on both sides with a semi-permeable membrane. The space in between contains Chelex-100 beads, which bind metals. The AM allows the determination of the dissolved, bioaccessible metal fraction in water bodies without killing organisms, as well as environments with unfavorable conditions for living bioindicators. In the present study, the use of the AM was adapted for the monitoring of platinum (Pt) in a freshwater ecosystem.

Results: The elution of Pt from the Chelex-100 beads was optimized. Two modifications to the original method for the use of AMs are recommended, i.e., washing and separation of the beads through centrifugation and elution with a mixture of $4.5 \mathrm{~mL} \mathrm{HNO}$ and $0.5 \mathrm{~mL} \mathrm{HCl}$ for approximately $2-3 \mathrm{~h}$ to ensure the release of all Pt bound to the beads. Additionally, the uptake kinetics of the AM were determined under laboratory conditions over a wide exposure concentration range $(0.1-1000 \mathrm{\mu g} / \mathrm{L})$ showing highly correlated Pt accumulation in the AMs with the aqueous exposure concentration. For the tested Pt exposure concentrations of $0.1,1,10$, and $100 \mu \mathrm{g} / \mathrm{L}$, the Pt concentrations in the AMs increased during the exposure period of 6 weeks. At the highest exposure concentration of $1000 \mu \mathrm{g} / \mathrm{L}$, the increase stagnated after 3 weeks. To validate the AM in the field, the Pt accumulation of the AM was assessed together with that of freshwater clams (Corbicula fluminalis africana), muscle and liver tissue of the three fish species sharptooth catfish (Clarias gariepinus), common carp (Cyprinus carpio) and Mozambique tilapia (Oreochromis mossambicus), as well as water hyacinths (Eichhornia crassipes) at two sampling sites in the Pt mining area of South Africa.
\end{abstract}

Conclusion: Results from the present study showed that the AM is a promising tool to monitor Pt concentrations in the freshwater environment at contaminated sites.

Keywords: Passive sampling device, Metal accumulation monitoring, Chelex-100, Uptake kinetics, Animal replacement

*Correspondence: sonja.zimmermann@uni-due.de

${ }^{1}$ Water Research Group, Unit for Environmental Sciences

and Management, North-West University, Potchefstroom 2520, South

Africa

Full list of author information is available at the end of the article

\section{Background}

Monitoring of pollutants in the aquatic environment is necessary to fulfill legislative frameworks and directives. With the development of the Mussel Watch concept in the mid-1970s [1], the use of living organisms as 
biological indicators of environmental contaminants has become the mainstay of environmental monitoring. The use of bioindicators has several advantages since they can produce time-integrated results and are an indication of the bioaccessible fraction of metals in the environment $[2,3]$. However, the metal bioaccumulation in organisms can be affected by various factors, such as body weight, growth rate, age, reproduction, and nutrition status [4]. Leung et al. suggested that also accompanying contaminants can influence the metal bioaccumulation [3]. Therefore, the use of biological indicators for monitoring of, e.g., metals in freshwater and marine environments has several limitations and disadvantages [2]. These include at first the need to use living organisms that have to be killed to receive information on the biological availability of selected pollutants. Additionally, the variation in metal concentrations in the water column and sediment is affected by the particle size, organic content, and redox conditions [2].

To overcome these challenges, passive sampling methods have successfully been used to monitor the aqueous concentrations of a wide range of pollutants [5]. All passive sampling devices are based on the principle that the analytes freely flow from the sampling medium to a receiving phase in the device [5]. The analytes are trapped in the device, which is subsequently analyzed to determine the biologically available fraction (the ecotoxicologically relevant fraction) within the water column. These devices are advantageous since they provide timeintegrated estimates as opposed to the snapshot view of traditional water sampling, which is highly variable and may not be representative [6]. Most importantly, if the results obtained with passive sampling devices correspond to accumulation data using living bioindicators, they could replace the use of living bioindicators and thus reduce the number of animals to be killed, so that they could also contribute to the fulfillment of the $3 \mathrm{R}$ principle (primarily applicable to vertebrates) [7].

Wu and Lau [4] tested the suitability of different polymer-ligands as a novel chemical device for the monitoring of metal pollution in the aquatic environment. They found that the use of Chelex-100 beads had many advantages over the other polymer-ligands and developed an artificial monitoring device in 2007 [2]. The artificial mussel (AM) was originally developed for use in the marine environment but has been applied in freshwater environments as well [6,8-12]. This device consists of Chelex-100 beads that are suspended in either artificial seawater (marine) or ultrapure water (freshwater) within a Perspex tube with two semi-permeable gel membranes that form a plug on both ends of the tube [2]. The semipermeable membranes allow the passage of metal ions into the interstitial space where they bind to the chelating beads. The $\mathrm{AM}$ has been applied for the monitoring of a wide range of metals such as $\mathrm{Al}, \mathrm{As}, \mathrm{Cd}, \mathrm{Co}, \mathrm{Cr}, \mathrm{Cu}, \mathrm{Fe}$, $\mathrm{Hg}, \mathrm{Mn}, \mathrm{Ni}, \mathrm{Pb}, \mathrm{U}, \mathrm{V}$ and $\mathrm{Zn}[2,3,6,8-18]$.

Among the metals monitored, especially those that are potentially toxic deserve special attention. Platinum (Pt), which usually occurs only in extremely low concentrations in the environment [19], has been shown in recent years to not only increase in the environment due to anthropogenic activities, but also to exert adverse effects on biota at elevated concentrations [20-22].

South Africa is one of the largest producers of platinum in the world. In 2018 it was estimated that South Africa produced $73 \%$ of the world's platinum [23]. Recent studies have shown that the aquatic environments in the vicinity of Pt mines have elevated Pt concentrations in their sediments [24, 25]. A recent field study in a river system of a Pt mining area in South Africa demonstrated that the AM can accumulate Pt from the water column, therefore it was necessary to further investigate the accumulation behavior of the AM for this metal [12]. This field study demonstrated clear Pt uptake together with other metals such as $\mathrm{Cr}, \mathrm{Ni}$, and $\mathrm{Zn}$ by the AM. This supported findings of other studies where significantly positive correlations between metal uptake in notably marine bivalve biological indicators and AMs were found [3, 13, $17,18]$.

Therefore, the present study aimed (1) to optimize the analytical extraction of Pt from the Chelex-100 beads, which is necessary for a reliable analysis of the Pt accumulation in the AM; (2) to determine the concentrationdependent Pt uptake kinetics of the AM in freshwater over a wide exposure concentration range under laboratory conditions; (3) to validate the AM under field conditions as a reliable tool for monitoring bioavailable $\mathrm{Pt}$ concentrations in freshwater environments by comparing the Pt uptake of the AM with that of living organisms, i.e., different fish species and the water hyacinth, and (4) to comment on the appropriateness of the AM as an alternative to living organisms as biological indicators of metal exposure.

\section{Materials and methods \\ Validation of the efficiency of Chelex-100 beads to bind Pt}

To determine if Chelex-100 beads can accumulate Pt from the ambient environment, a short-term laboratory study was done to test (1) the binding of Pt to the Chelex-100 beads and (2) the most effective method of Pt elution from the Chelex-100 beads. The loading, washing, and elution experiment was conducted to check the practicability and validity of the washing and elution procedure. To determine the validity (recovery and precision), Chelex-100 beads were loaded with a defined 
concentration of Pt to determine the loading of the beads. Furthermore, it was necessary to confirm that Pt binds to the beads in ultrapure water as it is used in the AMs.

\section{Loading of Chelex-100 beads with Pt}

To test the loading capability of the Chelex-100 beads, $200 \mathrm{mg}$ beads (Sigma-Aldrich, sodium form, 50-100 mesh, dry) were placed in 15-mL polypropylene tubes. In total 20 polypropylene tubes were used, 10 of these tubes were loaded with $4.95 \mathrm{~mL}$ ultrapure water (loading solution 1) and $4.95 \mathrm{~mL} 0.5 \mathrm{M} \mathrm{HCl}$ (Merck, 37\%, suprapure) in the other 10 tubes (loading solution 2). In each of these tubes, $50 \mu \mathrm{L}$ of $100 \mathrm{mg} / \mathrm{L}$ Pt standard solution (Sigma-Aldrich, Pt standard for ICP TraceCERT ${ }^{\circledR}$, $1000 \mathrm{mg} / \mathrm{L}, \mathrm{Pt}(\mathrm{IV})$ in hydrochloric acid, diluted with $1 \%$ $\mathrm{HNO}_{3}$, sub-boiled from 65\%; p.a. quality, Merck) were added resulting in a final $\mathrm{Pt}$ concentration of $1 \mathrm{mg} / \mathrm{L}$. During the loading of the beads, the tubes were continuously shaken on a mechanical shaker (VWR International, VWR 5000 Advanced digital shaker). Samples were taken from the supernatant at several time intervals $(10,30,100,120$ and $210 \mathrm{~min})$ to determine the loading kinetics of the Chelex-100 beads and the Pt concentrations were immediately analyzed using a Perkin-Elmer model 4100ZL atomic absorption spectrometer (AAS) equipped with a Zeeman effect background correction system.

The samples were injected in a pyrolytic graphite furnace tube using the autosampler AS 70 and ran under the optimized operating parameters (Table 1). The calibration was performed by matrix adapted calibration where the concentrations in each sample were calculated by fitting a linear regression line to the points defined by the spiked concentration values.

\section{Washing of the Chelex-100 beads}

Following the removal of the tubes from the shaker, the Chelex-100 beads went through three repeated washing steps. This was done to eliminate any unbound Pt that

Table 1 Optimized operating parameters for platinum analysis by AAS

\begin{tabular}{llll}
\hline Temp $\left({ }^{\circ} \mathbf{C}\right)$ & Ramp time (s) & Hold time (s) & $\begin{array}{l}\text { Argon } \\
\text { flow } \\
\text { (psi) }\end{array}$ \\
\hline 110 & 1 & 5 & 250 \\
140 & 10 & 60 & 250 \\
600 & 20 & 1 & 250 \\
1300 & 30 & 20 & 250 \\
2200 & 0 & 3 & 0 \\
2450 & 1 & 3 & 250 \\
\hline
\end{tabular}

might have stayed in the tube or the loading solution. The supernatant in each of the tubes was carefully removed with a pipette and afterwards the Chelex-100 beads were resuspended in $5 \mathrm{~mL}$ ultrapure water. After centrifugation (2 min at $1000 \mathrm{~g}$ ) the washing solution was removed. The centrifugation ensured that the beads settle at the bottom of the tube before removing the supernatant again, this was repeated two more times. The Pt concentrations in the supernatant of the washing steps were also analyzed by AAS as described above to determine any Pt loss that may occur. At the end of the washing steps, only the Chelex-100 beads remained in the tubes. This is a new method for separating the beads from the solution as in former studies the separation of the beads was done by a more time-intensive filtration method [2].

\section{Elution procedure}

After washing the beads, the elution of the Pt from the Chelex-100 beads was tested with two different elution solutions. For the elution experiment, only the beads loaded in $0.5 \mathrm{M} \mathrm{HCl}$ were used due to better loading results. The first elution solution consisting of $4.5 \mathrm{~mL} 6 \mathrm{M}$ $\mathrm{HNO}_{3}$ (Merck, sub-boiled from 65\%; p.a. quality) and $0.5 \mathrm{~mL} 12 \mathrm{M} \mathrm{HCl}$ (Merck, 37\%, suprapure) was added to each of 4 tubes with Pt loaded beads. The second solution consisting of $5 \mathrm{~mL} 8 \mathrm{M} \mathrm{HCl}$ (prepared from Merck, 37\%, suprapure) was used on another 5 tubes. Samples were taken from the supernatant at several time intervals $(10$, $30 \mathrm{~min}, 1,2$ and $24 \mathrm{~h}$ ) to determine the elution kinetics from the Chelex-100 beads and immediately analyzed by AAS as described above.

\section{The artificial mussel design}

The artificial mussel device consists of a non-permeable Perspex tube, which contains $200 \mathrm{mg}$ Chelex-100 beads suspended in $5 \mathrm{~mL}$ ultrapure water (Fig. 1). The water diffuses into the cavity that contains the Chelex-100 beads through two polyacrylamide gel layers (semi-permeable membranes).

The protocol for assembling the artificial mussel was as follows: The end of each Perspex tube was covered with parafilm to form a membrane to prevent the solutions from seeping out while the gel polymerizes. The gel was composed of three solutions. The first solution consisted of $15 \mathrm{~g}$ acrylamide (Sigma, Acrylamide for electrophoresis, 99\% (HPLC) powder) and $0.5 \mathrm{~g} \mathrm{~N}, \mathrm{~N}$ methylenebis-acrylamide (Sigma, BioReagent, suitable for electrophoresis, 99\%) dissolved in $100 \mathrm{~mL}$ ultrapure water, of this $4 \mathrm{~mL}$ was pipetted into the plastic tubing. The second solution, i.e., $160 \mu \mathrm{L} \mathrm{10 \%}$ ammonium peroxidisulfate (Sigma, Reagent grade, 98\%), and the third solution, i.e., $40 \mu \mathrm{L} \mathrm{N}, \mathrm{N}, \mathrm{N}^{\prime}, \mathrm{N}^{\prime}$-tetramethylethylenediamine 


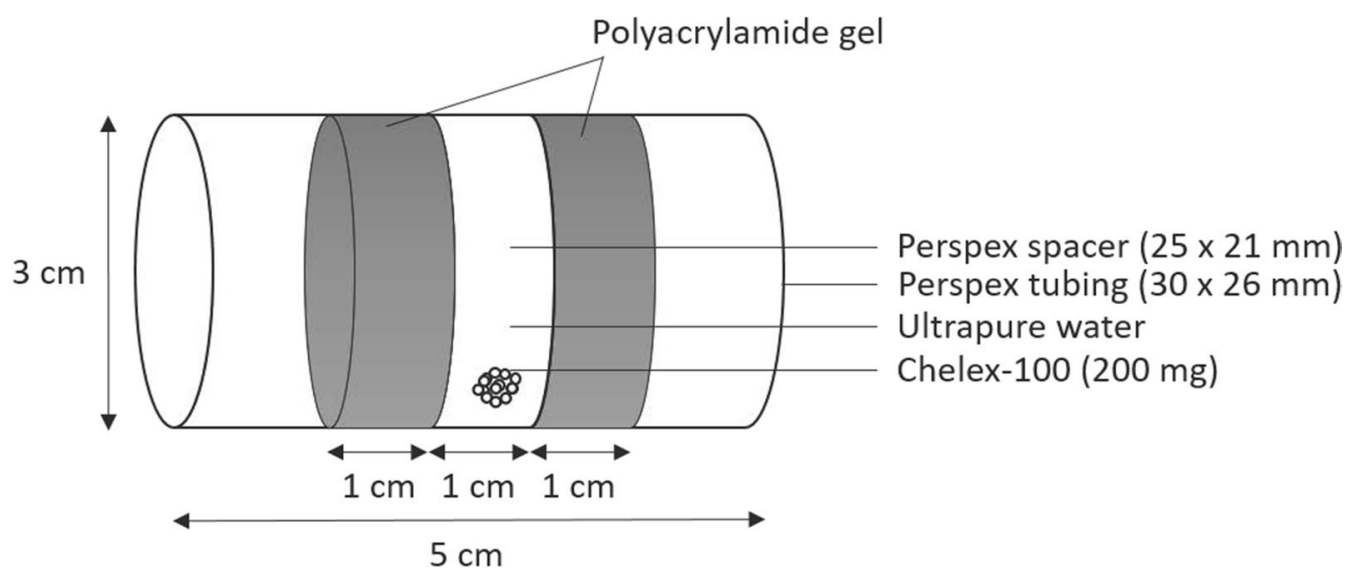

Fig. 1 Graphical representation of the artificial mussel (adopted from [2, 12]). For both the Perspex spacer and tubing, the sizes given in the brackets represent the external and internal diameters

(Sigma, BioReagent, for molecular biology, 99\% (GC)), were added to form the semi-permeable gel membranes $[10,12]$.

Following the gel polymerizing (usually within $5 \mathrm{~min}$ ), the tubes with the gels were placed in a container filled with ultrapure water for $1 \mathrm{~h}$, this allows the gels to swell. After $1 \mathrm{~h}$ of swelling, the gels were carefully moved to the desired position within the tube by cautiously rubbing in a circular motion on the gel surface until it moved. A $1 \mathrm{~cm}$ Perspex spacer was then placed within the tube with $200 \mathrm{mg}$ Chelex-100 beads and $5 \mathrm{~mL}$ ultrapure water. The second gel was then carefully transferred into the tube until firmly positioned against the spacer, making sure that no air bubbles were trapped in between the two gel layers. After assembly, the AMs were stored in ultrapure water until needed.

\section{Long-term exposure of the artificial mussels to a series of $\mathrm{Pt}$ concentrations \\ Experimental design}

To validate the Pt uptake by the AM, a static exposure study with a series of increasing dissolved Pt concentrations was performed. The AMs were divided into six experimental groups (Table 2). The nominal Pt concentrations in the tank water were $0,0.1,1,10,100$ and $1000 \mu \mathrm{g} / \mathrm{L}$. Platinum standard solution (Sigma-Aldrich, Pt standard for ICP TraceCERT ${ }^{\circledR}, 1000 \mathrm{mg} / \mathrm{L}, \mathrm{Pt}(\mathrm{IV})$ in $2 \mathrm{M}$ hydrochloric acid), as well as $\mathrm{HCl}(2 \mathrm{~mol} / \mathrm{L})$, were added to 10-L exposure medium according to Table 2.

Six plastic tanks $(300 \times 750 \mathrm{~mm})$ lined with polypropylene (PP) bags (Sarstedt, disposable bags, autoclavable, $600 \times 780 \mathrm{~mm}$ ) were filled with deionized water to rinse the bags and to check for any leakages [22]. By lining the tanks with PP bags, which were discarded after the exposure study, it is possible to reuse the plastic tanks. All tanks were aerated in the same way using air stones, which also allowed for the continuous movement of the water and a permanent mixing of Pt within the tank.

After $24 \mathrm{~h}$ the deionized water in the PP bags was discarded and replaced with $10 \mathrm{~L}$ reconstituted freshwater [22]. The Pt standard solution was added to the tanks as indicated in Table 2. The bags were pre-conditioned to saturate the surfaces of the PP bags with Pt before the exposure commenced. This pre-conditioning step was done to minimize the loss of Pt due to adsorption processes on the bag surfaces during the exposure.

Table 2 Experimental layout for Pt exposures

\begin{tabular}{llllll}
\hline & Experimental group & \# AMs/sampling & \# AMs/tank & & Addition of \\
\cline { 4 - 6 } & & & & Pt standard (1 g/L) & HCl (2 mol/L) \\
\hline Tank 1 & Control & 7 & 42 & None & $10 \mathrm{~mL}$ \\
Tank 2 & $0.1 \mu \mathrm{g} \mathrm{Pt} / \mathrm{L}$ & 7 & 42 & $1 \mu \mathrm{L}$ & $10 \mathrm{~mL}$ \\
Tank 3 & $1 \mu \mathrm{g} \mathrm{Pt} / \mathrm{L}$ & 7 & 42 & $10 \mu \mathrm{L}$ & $10 \mathrm{~mL}$ \\
Tank 4 & $10 \mu \mathrm{gt} / \mathrm{L}$ & 7 & 42 & $100 \mu \mathrm{L}$ & $9.9 \mathrm{~mL}$ \\
Tank 5 & $100 \mu \mathrm{g} \mathrm{Pt} / \mathrm{L}$ & 7 & 42 & $1 \mathrm{~mL}$ & $10 \mathrm{~mL}$ \\
Tank6 & $1000 \mu \mathrm{gPt} / \mathrm{L}$ & 7 & 42 & & $\mathrm{None}$ \\
\hline
\end{tabular}


Following the pre-conditioning period of $24 \mathrm{~h}$, the water was replaced with new exposure medium and Pt standard solution, as described above, and left for another $24 \mathrm{~h}$ before 42 AMs were added to each tank.

\section{Water sampling and removal of AMs}

Water samples were taken from each tank at different intervals: 1) before the addition of the Pt, 2) 10 min after the addition of the Pt standard solution, 3) before the addition of the AMs, and 4) subsequently weekly before AMs were removed. The procedures were as follows: $10 \mathrm{~mL}$ tank water was transferred into $15 \mathrm{~mL}$ polypropylene tubes and acidified immediately with $10 \mu \mathrm{L} \mathrm{HNO}_{3}$ (Merck, sub-boiled from 65\%; p.a. quality). Additionally, AM samples $(n=7)$ were taken once every week over six weeks. The AMs were plugged at both ends with cotton soaked in ultrapure water, placed in plastic bags, marked and stored at room temperature for metal analysis.

\section{Platinum analysis}

For the determination of the Pt accumulated in the AMs, the Chelex-100 beads were removed from the AMs by gently moving the gel layer to one end of the AM by carefully rubbing with the finger against the opposite gel layer until the interspace moves. For metal analysis, the content (including the Chelex-100 beads) of each individual AM was emptied and rinsed out with ultrapure water into an acid pre-washed $15 \mathrm{~mL}$ polypropylene tube. These samples were then centrifuged ( $2 \mathrm{~min}$ at $1000 \mathrm{~g}$ ), the supernatant was removed and the beads were rinsed with $5 \mathrm{~mL}$ ultrapure water. This washing step was repeated in total three times. The supernatant was removed and the beads were eluted with $4.5 \mathrm{~mL} 6 \mathrm{M} \mathrm{HNO}_{3}$ (sub-boiled from 65\%; p.a. quality, Merck) and $0.5 \mathrm{~mL} \mathrm{HCl} \mathrm{(Merck,}$ $37 \%$, suprapure). The beads were placed on a mechanical shaker to eluate the Pt from the Chelex-100 beads in the acid solution for approximately $2 \mathrm{~h}$. This was based on the results obtained from the elution experiment, to ensure that all bound metals would be released from the beads. The supernatant was removed and placed in new polypropylene tubes for further analysis.

Accordingly, Pt concentrations in the water and AMs were determined by a quadrupole Inductively Coupled Plasma Mass Spectrometry (ICP-MS, Perkin-Elmer Elan 6000 with autosampler system Perkin-Elmer AS-90). For ICP-MS analysis, the wash time was set to $30 \mathrm{~s}$ with $2 \%$ $\mathrm{HNO}_{3}$ to avoid contamination. After every 10 samples, a Pt standard solution $(10 \mu \mathrm{g} / \mathrm{L})$ was measured to check the accuracy and stability of the measurements. Before ICP-MS measurement, samples were diluted 1:10 with an internal standard solution, consisting of $1 \% \mathrm{HNO}_{3}$ and $10 \mu \mathrm{g} / \mathrm{L}$ thulium (Merck, Certipur ${ }^{\circledR}$ ). Calibration of the instrument was performed using a series of 11 dilutions of Pt standard solution (Sigma-Aldrich, Pt standard for ICP TraceCERT $\left.{ }^{\circledR}, 1000 \mathrm{mg} / \mathrm{L}\right)$. With this, the concentrations of the sample analytes were calculated using regression lines with a correlation factor of $\geq 0.999$ for the Pt-194 mass line.

Interferences can have an effect on the Pt measured by the analytical instruments. To check for hafnium (Hf) oxide interferences at that mass line, a series of 5 dilutions of increasing $\mathrm{Hf}$ concentrations were measured. The Hf interferences on Pt-194 were below 2\%, thus mathematical correction was not necessary. The limit of detection (LOD) for the AMs in the long-term laboratory exposure was $0.47 \mathrm{ng}$ Pt/AM, for the water in the laboratory the detection limit was $0.045 \mu \mathrm{g} \mathrm{Pt} / \mathrm{L}$. Besides the exposed AMs, seven unexposed AMs were analyzed to determine the Pt background concentration in the AMs, which was below LOD.

\section{Field study on the Pt accumulation in artificial mussels in comparison with living organisms}

In addition to the laboratory investigations, field sampling of living organisms was combined with active monitoring using AMs (described in detail in Labuschagne et al. [12]) at two impoundments within the same catchment (Hex River) in the Pt mining area of South Africa in March 2018. In Olifantsnek Dam, the Pt exposure only originates from geogenic sources, while Bospoort Dam is downstream of various anthropogenic activities, such as intensive Pt mining and refining activities as well as industrial and urban effluents (see Erasmus et al. [26] and Labuschagne et al. [12] for more detail). In situ physico-chemical variables of the water including electrical conductivity (EC), pH and temperature (ExStik II EC500, Extech Instruments), as well as dissolved oxygen (DO) (ExStik II DO600, Extech Instruments) were measured at the two impoundment sites.

Water samples were collected in triplicate in precleaned polyethylene containers, filtered (Cellulose nitrate filter, $0.45 \mu \mathrm{m}$, Sartorius Stedim Biotech) and then analyzed for inorganic nutrients and Pt. Water samples were collected in the water column from different sites within the impoundments, where the AMs were deployed, in the middle and then closer to the banks of the impoundment. The samples were collected at kneehigh depth on the side of the impoundment and close to the surface for the other two samples. The water samples were analyzed for nutrients $\left(\mathrm{NH}_{4}{ }^{+}, \mathrm{NO}_{3}{ }^{-}, \mathrm{NO}_{2}{ }^{-}, \mathrm{PO}_{4}{ }^{3-}\right)$ and other chemical water quality variables $\left(\mathrm{Cl}^{-}, \mathrm{SO}_{4}{ }^{2-}\right.$ and turbidity) using a spectrophotometer (Spectroquant Pharo 300, Merck) and Merck Spectroquant test kits. For metal analysis, $10 \mathrm{~mL}$ water was taken and acidified with $10 \mu \mathrm{L} \mathrm{HNO}_{3}$ (sub-boiled from 65\%; p.a. quality, Merck, Darmstadt, Germany) and stored in polypropylene tubes 
at room temperature. Sediment samples were collected in triplicate from the upper $10 \mathrm{~cm}$ of the substratum in pre-cleaned polyethylene containers for organic content $(\mathrm{OC})$, particle size distribution and Pt analysis. The percentage of organic content and the particle size distribution were determined according to the methods described in Erasmus et al. [24]. Sediment particle size was characterized as: gravel $(>4,000 \mu \mathrm{m})$, very coarse sand $(4000-2000 \mu \mathrm{m})$, coarse sand $(2000-500 \mu \mathrm{m})$, medium sand $(500-212 \mu \mathrm{m})$, fine sand $(212-65 \mu \mathrm{m})$ and mud $(<65 \mu \mathrm{m})$. Samples of the mud fraction $(<65 \mu \mathrm{m})$, which is known to contain the highest Pt concentration among all fractions, were prepared for Pt analysis following the methods described in Erasmus et al. [24]. Water samples were analyzed for Pt concentrations as described for the laboratory exposure samples.

During the 6 weeks exposure of the AMs in the two impoundments, living bioindicator organisms, i.e., the freshwater clam Corbicula fluminalis africana (shell length $28 \pm 5 \mathrm{~mm}$, Labuschagne et al. [12]), the fish species sharptooth catfish (Clarias gariepinus), common carp (Cyprinus carpio) and Mozambique tilapia (Oreochromis mossambicus) were sampled from the same sites as in Labuschagne et al. [12] and Erasmus et al. [26]. The AMs were deployed near the bottom of the impoundments. The condition factors of the fish from Olifantsnek Dam and Bospoort Dam were 0.94 \pm 0.10 and $1.17 \pm 0.24$ for sharptooth catfish, $2.44 \pm 0.22$ and $2.78 \pm 0.49$ for common carp, as well as $2.89 \pm 0.22$ and $2.85 \pm 0.37$ for Mozambique tilapia, respectively. Muscle and liver of the fish were analyzed by ICP-MS after microwave digestion according to Erasmus et al. [24, 26]. At Bospoort Dam, i.e., the impoundment impacted with anthropogenic activities, water hyacinth (Eichhornia crassipes) was also assessed as this plant is known to accumulate Pt [27, 28 ]. The plants were randomly picked by hand, well precleaned with ambient water and placed in plastic bags for transportation to the laboratory. In the laboratory, the plants were carefully rinsed with distilled water and then divided into roots, stems and leaves. After freezedrying (FreeZone 6, Labconco) and homogenization in a ceramic mortar and pestle, the Pt concentrations of the different plant parts were determined as described for the animal tissues.

\section{Statistical analyses}

Statistical analyses were performed using GraphPad Prism ${ }^{\circledR} 7$ software. Platinum uptake of the AM in the lab experiments are expressed in ng/AM and the field study in $\mu \mathrm{g} / \mathrm{g}$ related to $200 \mathrm{mg}$ Chelex for a better comparison with the fish tissues. The correlation of Pt uptake by the AM (mean of seven AMs per sampling time) and the respective exposure concentrations was determined by linear regression. The water quality data from March 2018 (from Labuschagne et al. [12]) contained one outlier value, which was discarded for statistical reasons for this study. For both water and sediment, Shapiro-Wilk normality test indicated that data were distributed normally, where significant differences in Pt concentrations between Olifantsnek Dam and Bospoort Dam were determined by using Welch's t-test. To evaluate the usefulness of the AM, a two-way ANOVA was performed to compare only the bioindicator organisms from the same impoundment, followed by Tukey's multiple comparisons test. To compare the concentrations in the organisms between the two impoundments, a two-way ANOVA was performed, followed by Sidak's multiple comparisons test. Significance was set at $\mathrm{p}<0.05$ for all comparisons.

\section{Results}

\section{Binding and elution of $\mathrm{Pt}$ from Chelex-100}

The loading experiment indicated that $\mathrm{Pt}$ was bound in both loading solutions to the Chelex-100 beads as there was a significant loss of $\mathrm{Pt}$ in the loading solutions over time (Fig. 2). However, the Chelex-100 loading kinetics differed for the two different loading solutions. The Pt concentration of loading solution 1 (ultrapure water) was relatively stable during the loading period and contained about $45 \%$ of the initially added Pt concentration after $200 \mathrm{~min}$. In contrast, the Pt concentrations of loading solution $2(0.5 \mathrm{M} \mathrm{HCl})$ decreased over time and contained only $13 \%$ of the initially added Pt concentration after $200 \mathrm{~min}$. Thus, it can be assumed that in $0.5 \mathrm{M} \mathrm{HCl}$ a much higher part of the Pt was loaded to the Chelex beads than in ultrapure water. The decline of the Pt concentration in the loading solutions can be attributed to the binding of $\mathrm{Pt}$ to the Chelex-100 beads as respective controls without Chelex-100 beads showed no decline in

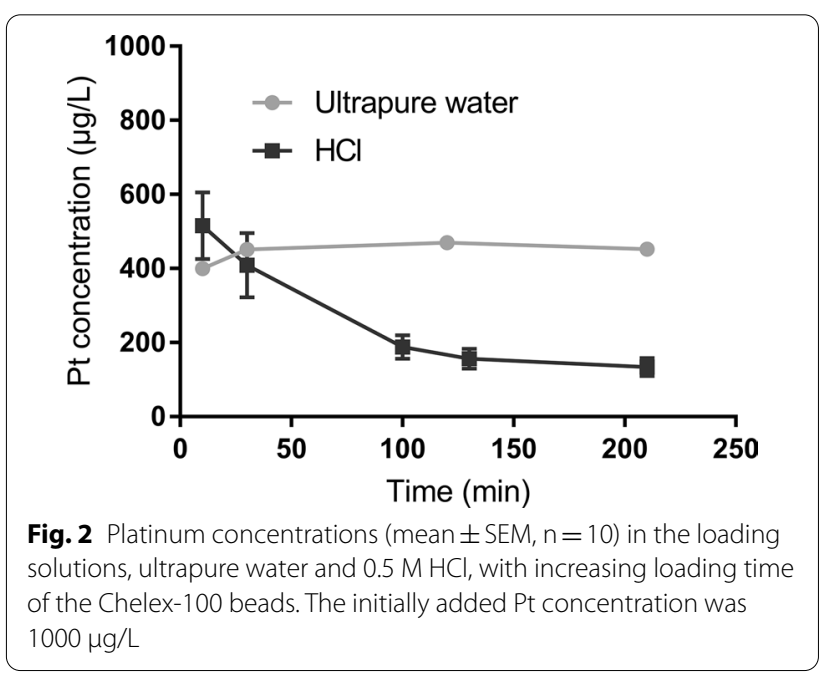


the Pt concentration over time (data not shown). Additionally, mass balance calculations showed that the sum of the Pt mass in the loading solution and the Pt mass in the elution solution was equal to the initially added $\mathrm{Pt}$ mass.

The washing of the beads through centrifugation was very effective. Following the first washing step, only $1 \%$ of the added Pt was found in the wash solution. Following the second and the third washing step, no Pt was detectable in the wash solution. For the elution experiment, only the beads loaded in $0.5 \mathrm{M} \mathrm{HCl}$ were used due to better loading results. Immediately after the elution solution was added to the beads, the Pt concentrations in the supernatant started to increase, whereas the highest Pt concentrations were reached after 120 min (Fig. 3). Considering that during the loading process $87 \%$ of the initially added Pt was bound to the Chelex-100 beads, the elution rate of the mixture of $4.5 \mathrm{~mL} 6 \mathrm{M} \mathrm{HNO}_{3}$ and $0.5 \mathrm{~mL} 12 \mathrm{M} \mathrm{HCl}$ was $115 \%$ and thus much higher when compared with the elution rate of $86 \%$ of $8 \mathrm{M} \mathrm{HCl}$.

\section{Concentration-dependent Pt uptake kinetics by the artificial mussel}

During the long-term exposure, Pt uptake was found in all Pt-exposed AMs (Fig. 4). However, for the $0.1 \mu \mathrm{g} / \mathrm{L}$ group the Pt mass measured in the AMs (i.e., the Pt mass bound to $200 \mathrm{mg}$ Chelex-100 beads) exceeded the detection limit of $0.47 \mathrm{ng} \mathrm{Pt} / \mathrm{AM}$ only after 6 weeks of exposure. In all higher exposed groups, the Pt mass increased already after one week of exposure (Fig. 4). The Pt masses in the AMs increased throughout the entire 6-week exposure period in all Pt-exposed tanks, except for the $1000 \mu \mathrm{g} / \mathrm{L}$ group. In this tank, the Pt masses increased during the first 3 weeks of exposure, followed by a slight decrease during the next 3 weeks (Fig. 4 E).

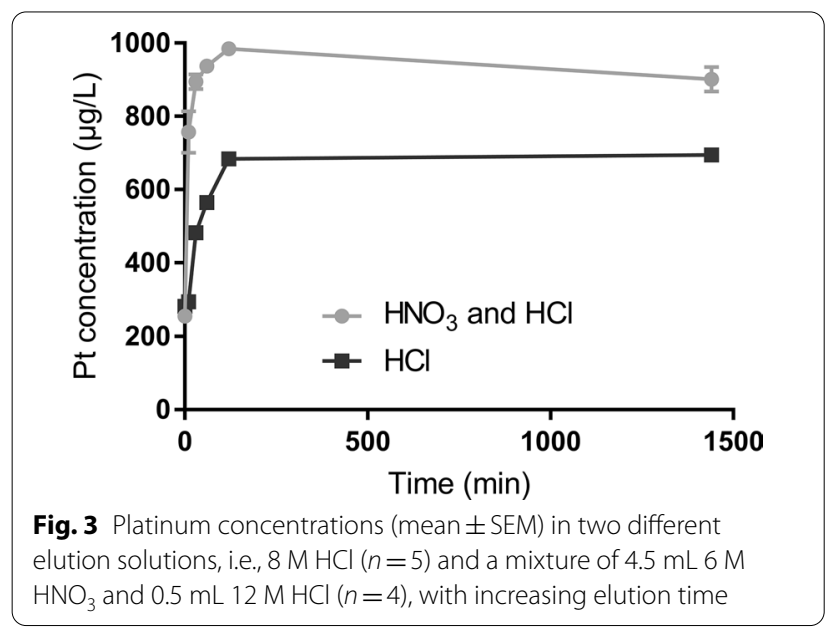

The analyzed Pt concentration in the tank water and the Pt uptake by the AMs were positively correlated, which indicated that the Pt mass in the AMs increased with increasing exposure concentration (Fig. 5).

\section{Pt accumulation in artificial mussels in comparison with living organisms under field conditions}

The Pt accumulation in AMs and living organisms, i.e., different fish species, were determined under field conditions at two different impoundments of a Pt mining area. To better characterize these impoundments, water and sediment quality parameters (Table 3 ), as well as the $\mathrm{Pt}$ concentrations (Fig. 6) were analyzed.

Olifantsnek Dam (geogenic Pt source) had higher dissolved oxygen, turbidity, suspended solids and $\mathrm{pH}$ in the water, as well as a higher percentage of fine sand $(212-65 \mu \mathrm{m})$ and mud $(<65 \mu \mathrm{m})$ in the sediment than Bospoort Dam. In contrast, Bospoort Dam had very high electrical conductivity (EC) values during the field survey, as well as anions $\left(\mathrm{Cl}^{-}, \mathrm{SO}_{4}{ }^{2-}\right)$ and nutrients $\left(\mathrm{NH}_{4}{ }^{+}\right.$, $\mathrm{PO}_{4}{ }^{3-}$ ) in the water, together with coarser sediment particles in the sediment. The chloride concentration was 20 times higher in Bospoort Dam than in Olifantsnek Dam. However, Olifantsnek Dam had higher nitrate $\left(\mathrm{NO}_{3}{ }^{-}\right)$ and nitrite $\left(\mathrm{NO}_{2}{ }^{-}\right)$values.

Platinum concentrations in the water taken from the same sampling sites as the AMs and fish, were significantly higher in Bospoort Dam when compared to Olifantsnek Dam (Fig. 6a). In contrast, the sediment samples, which were only taken at the fish sampling site, showed an opposite pattern between the two impoundments (Fig. 6b).

Although there were significant differences in the Pt concentrations of the water and sediment between both impoundments, significant differences between Pt accumulation in the fish and AM occurred only between the two impoundments for the muscle and liver of $C$. carpio and C. gariepinus and always with higher Pt concentrations at Bospoort Dam than at Olifantsnek Dam (Fig. 7). For the AMs and the muscle and liver of O. mossambicus similar Pt concentrations were found at both impoundments.

There was no significant difference between the $\mathrm{Pt}$ accumulation in the AM and the different fish species from Olifantsnek Dam, while in Bospoort Dam muscle and liver of C. carpio and liver of C. gariepinus showed significantly higher Pt concentrations than those measured in the AM. In Bospoort Dam, E. crassipes were also analyzed and separated in the different sections of the plant: root, stems and leaves. The roots of E. crassipes contained significantly higher $\mathrm{Pt}$ concentrations than all the other organisms tested in the field study (Fig. 7). 


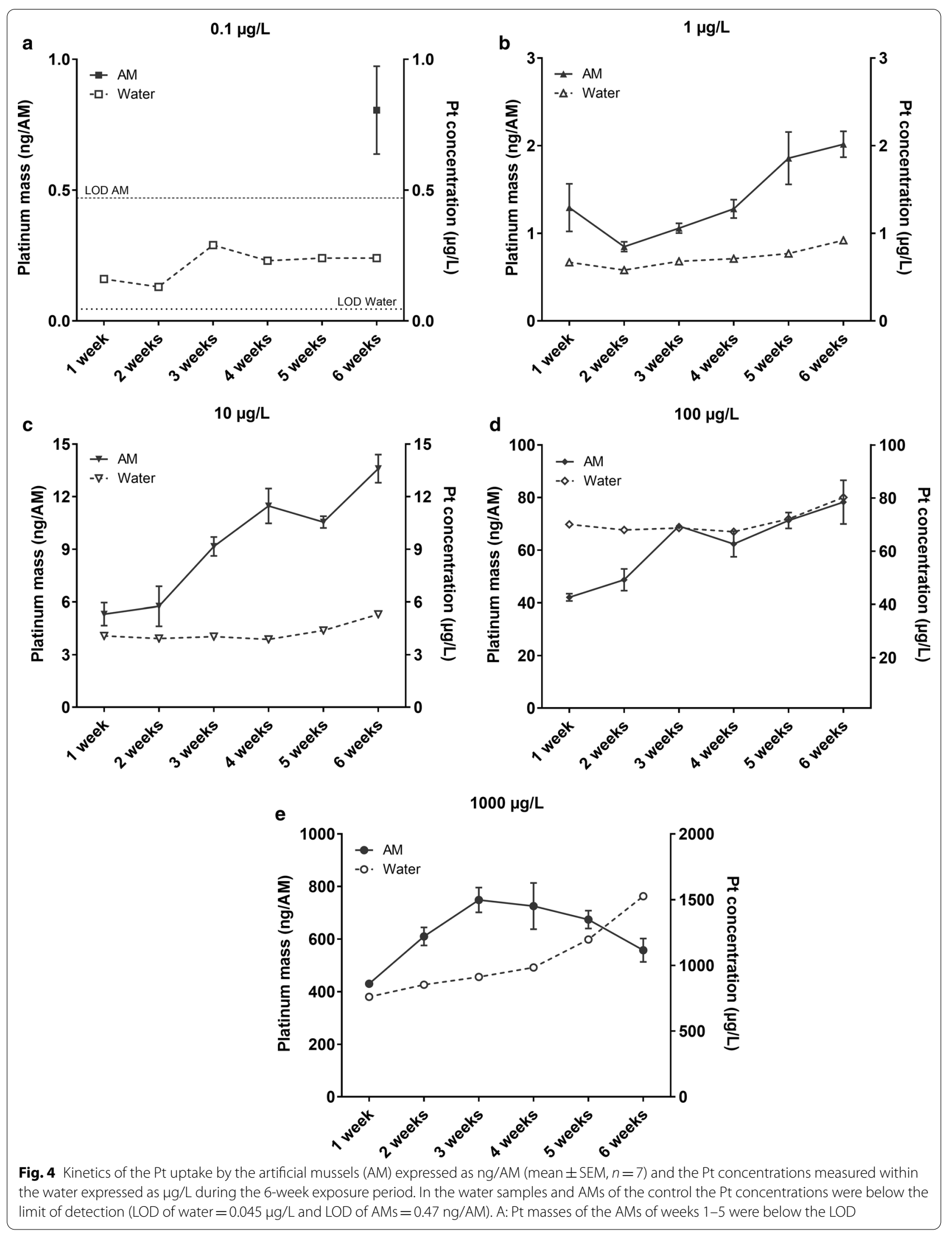




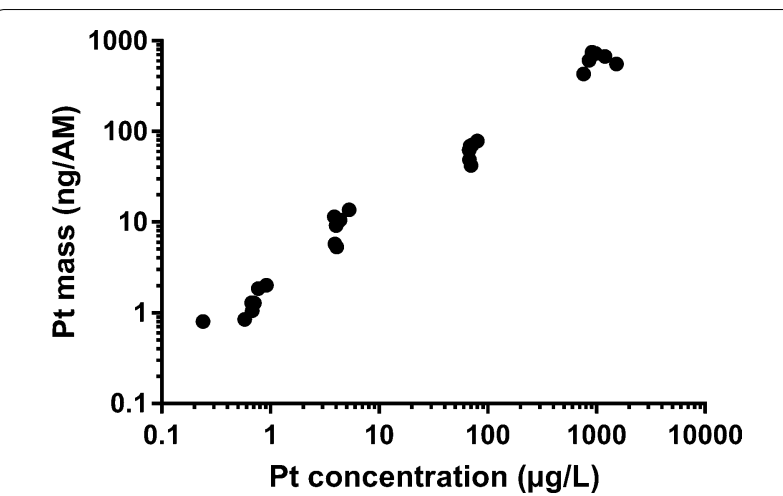

Fig. 5 Correlation of Pt uptake by the AM and the determined exposure concentrations in the tank water. The $x$ - and $y$-axis are presented in logarithmic scale. Linear regression analysis revealed for the regression line the following equation: $y=0.5502 x+20.13$; $R^{2}=0.8915$

The Pt levels in the freshwater clam from both impoundments were below detection limits [12].

\section{Discussion}

In the present study, two solutions were used to test the loading of the Chelex-100 beads with Pt. The ultrapure water was selected since in previous studies the beads were suspended in ultrapure water within the AM $[6,10]$. The second loading solution was a diluted hydrochloric acid solution $(0.5 \mathrm{M} \mathrm{HCl})$ since metals forming stable chloride complexes, including $\mathrm{Pt}$, show the highest affinity towards Chelex-100 in diluted $(0.1-1.0 \mathrm{M}) \mathrm{HCl}$ solutions [29].

In the loading experiment, using ultrapure water as loading solution approximately half of the initially added Pt remained in the loading solution for the duration of the experiment (Fig. 2). Based on these results, it can be concluded that in ultrapure water only about $50 \%$ of the Pt had bound to the Chelex-100 beads. As the loading of Pt to the Chelex-100 beads were more effective in a $0.5 \mathrm{M} \mathrm{HCl}$ solution, only the tubes from this loading were used for the elution experiment. However, about $13 \%$ of the initially added Pt remained in solution when equilibrium conditions were reached. In the present study, ultrapure water was used as a suspension medium for the Chelex-100 beads in the AMs according to previously published studies (Table 4).

Since the original development of the AM, some modifications regarding the elution of metals from the Chelex-100 beads have been made. The earlier methods involved emptying the contents of each AM into a sintered glass filter followed by eluting twice with $12.5 \mathrm{~mL}$ $6 \mathrm{M} \mathrm{HNO}_{3}$. The elutriant was then made up to a known

Table 3 Water and sediment characteristics (mean \pm SD) measured in Olifantsnek and Bospoort Dams during the field exposure

\begin{tabular}{|c|c|c|c|}
\hline & Code & Olifantsnek Dam & Bospoort Dam \\
\hline \multicolumn{4}{|l|}{ Water parameters } \\
\hline $\mathrm{pH}$ & $\mathrm{pH}$ & $8.1 \pm 0.2$ & $7.4 \pm 0.4$ \\
\hline Electrical conductivity $(\mu \mathrm{S} / \mathrm{cm})$ & $\mathrm{EC}$ & $200 \pm 15$ & $1356 \pm 277$ \\
\hline Temperature $\left({ }^{\circ} \mathrm{C}\right)$ & Temp & $23.8 \pm 0.7$ & $25.7 \pm 3.7$ \\
\hline Dissolved oxygen (mg/L) & DO & $8.0 \pm 3.6$ & $5.5 \pm 3.7$ \\
\hline Turbidity (FAU) & Turb & $38 \pm 5$ & $9 \pm 2$ \\
\hline Ammonium (mg/L) & $\mathrm{NH}_{4}^{+}$ & $0.02 \pm 0.01$ & $0.13 \pm 0.01$ \\
\hline Nitrate (mg/L) & $\mathrm{NO}_{3}^{-}$ & $0.32 \pm 0.04$ & $0.14 \pm 0.05$ \\
\hline Nitrite (mg/L) & $\mathrm{NO}_{2}^{-}$ & $0.007 \pm 0.004$ & $0.004 \pm 0.001$ \\
\hline Ortho-phosphate (mg/L) & $\mathrm{PO}_{4}^{3-}$ & $0.04 \pm 0.01$ & $0.20 \pm 0.01$ \\
\hline Chloride (mg/L) & $\mathrm{Cl}^{-}$ & $12 \pm 1.0$ & $240 \pm 3.8$ \\
\hline Sulfate (mg/L) & $\mathrm{SO}_{4}^{2-}$ & $86 \pm 4.7$ & $233 \pm 3.8$ \\
\hline Suspended solids (mg/100 mL) & SS & $3.8 \pm 2.8$ & $1.9 \pm 1.1$ \\
\hline \multicolumn{4}{|l|}{ Sediment parameters } \\
\hline Organic content (\%) & OC & $3.4 \pm 1.4$ & $2.3 \pm 0.5$ \\
\hline Gravel (\%) & G & $0.3 \pm 0.2$ & $5.9 \pm 3.6$ \\
\hline Very coarse sand (\%) & VCS & $0.5 \pm 0.2$ & $6.4 \pm 3.9$ \\
\hline Coarse sand (\%) & CS & $2.6 \pm 0.8$ & $26.1 \pm 9.9$ \\
\hline Medium sand (\%) & MS & $9.6 \pm 6.7$ & $34.5 \pm 5.6$ \\
\hline Fine sand (\%) & FS & $73.1 \pm 1.6$ & $22.7 \pm 3.9$ \\
\hline Mud (\%) & M & $13.9 \pm 9.1$ & $4.3 \pm 1.0$ \\
\hline
\end{tabular}



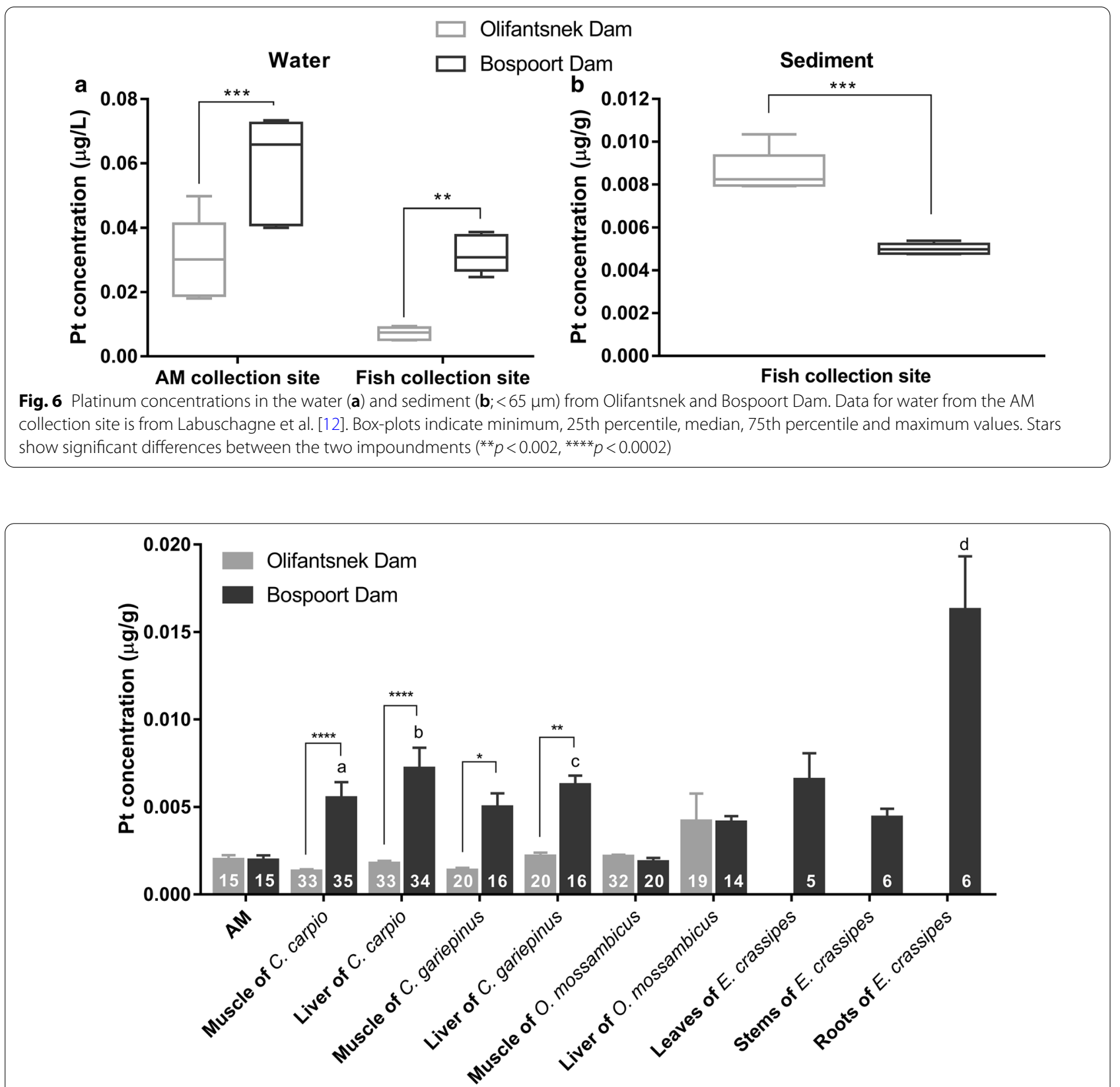

Fig. 7 Platinum concentrations (mean \pm SEM) measured in AMs (in $\mu \mathrm{g} / \mathrm{g}$ related to the Pt mass accumulated on 200 mg Chelex-100 beads; data from Labuschagne et al. [12]) and muscle and liver of three different fish species and the water hyacinth, from two impoundments (Olifantsnek Dam and Bospoort Dam) of a Pt mining area in South Africa. Bars with letter superscript represent a significant difference from AM of the same sampling site $(p<0.05)$, stars show significant differences between the two impoundments $\left({ }^{*} p<0.03,{ }^{* *} p<0.002,{ }^{* * * *} p<0.0001\right)$. Numbers within the bars represent the number of replicates $(n)$

volume with ultrapure water $[2,3,8,9,11,15,16]$, while Degger et al. [13] rinsed the beads with ultrapure water several times before eluting with $6 \mathrm{M} \mathrm{HNO}_{3}$. Another adapted version of this method consisted of rinsing the gel membrane and Chelex-100 beads with ultrapure water three times and then adding $10 \mathrm{~mL} 6 \mathrm{M} \mathrm{HNO}_{3}$ [14]. Other AM users emptied the content of each AM into a sintered glass filter, where after the Chelex-100 beads were placed in glass conical flasks in $20 \mathrm{~mL} 6 \mathrm{M}$ $\mathrm{HNO}_{3}$. These flasks with the content were then mixed on a shaker plate for $24 \mathrm{~h}[6,10]$. The most recent method entailed that the resin was placed on a glass funnel covered by filter paper where after the resin was rinsed 3 times with ultrapure water and washed with $10 \mathrm{~mL} \mathrm{70 \%}$ 


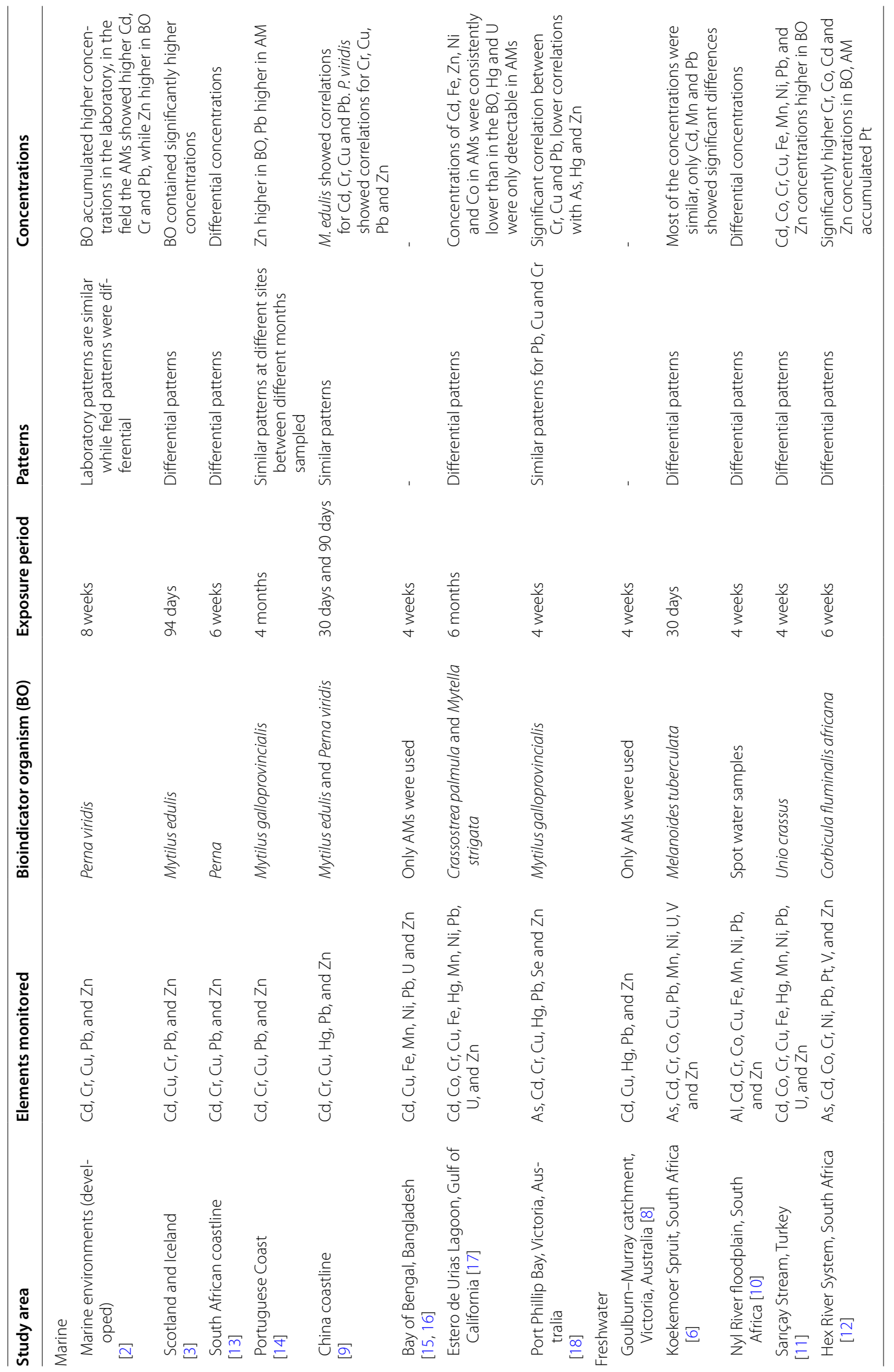


$\mathrm{HNO}_{3}$ [18]. In the present study, the Chelex-100 beads went through several washing steps by means of centrifugation. There were detectable (but low) Pt concentrations in the first washing solution, whereas no Pt was detectable in the second and third washing solutions, indicating that washing the beads by means of centrifugation is efficient. In comparison to previous studies, the washing method of the present study is more practical and less time-consuming when compared to the traditional filtration method.

According to literature, all AM studies (except for Labuschagne et al. [12]) used the same elution solution (i.e., $6 \mathrm{M} \mathrm{HNO}_{3}$ ). However, because $\mathrm{Pt}$ forms stable $\mathrm{Pt}$ chloro-complexes in $\mathrm{HCl}$ solution, $\mathrm{HCl}$ was added to the $\mathrm{HNO}_{3}$ in the first elution solution [29]. The second elution solution $(8 \mathrm{M} \mathrm{HCl})$ was used since it was shown in former studies that $8 \mathrm{M} \mathrm{HCl}$ solution eluted $95 \pm 2 \%$ of the Chelex-bound Pt [29]. In the present study, the mixture of $\mathrm{HNO}_{3}$ and $\mathrm{HCl}$ as elution solution revealed an elution rate of $115 \%$ and was clearly more effective than the second elution solution $(8 \mathrm{M} \mathrm{HCl})$, which had an elution rate of only $86 \%$. The elution experiment demonstrated that an elution period of approximately $2-3 \mathrm{~h}$ is sufficient, since the Pt concentration in the eluent remained constant thereafter. In comparison, in former studies, the metals were eluted in nitric acid over a period that ranged from a few seconds to $24 \mathrm{~h}$ (see references in Table 4). This is the first study that gives information regarding the efficiency of the elution period or elution rate of $\mathrm{Pt}$ from the Chelex-100 beads.

The second aim of the present study was to obtain a better understanding of the accumulation behavior of $\mathrm{Pt}$ in the AM. To this end, the concentration-dependent Pt uptake kinetics of the AM over a wide exposure concentration range were determined under laboratory conditions (Fig. 4). Except for the highest exposure group $(1000 \mu \mathrm{g} / \mathrm{L})$, the Pt concentrations in the AMs increased over the whole 6-week exposure period and steady-state conditions were not reached indicating that the binding capacity of the $200 \mathrm{mg}$ Chelex-100 beads was not reached. However, at an exposure concentration of $1000 \mu \mathrm{g} / \mathrm{L}$, which is far above any environmentally relevant Pt concentrations, the capacity of the Chelex-100 beads seems to be saturated. Nevertheless, the Pt accumulation by the AM showed a strong linear correlation with the Pt concentration in the exposure medium (Fig. 5). This relationship is important when using the AM for monitoring purposes as it makes it possible to draw conclusions about the environmental Pt contamination, exactly the dissolved, bioaccessible Pt concentration in the water phase, via the Pt accumulation in the AM. In Wu et al. [2], the uptake kinetics and depuration of the AM were compared to those of Perna viridis at different salinities and even though there was a difference in the concentrations between the AM and $P$. viridis the patterns were the same.

The main purpose of the field survey was to determine the efficiency of the AM to accumulate Pt under field conditions in comparison to living test organisms. The AMs took up Pt at both sampling sites. However, Pt concentrations of the AMs from the two impoundments were identical, although the two selected sampling sites for this fieldwork differed significantly in the Pt concentrations of the water and sediment $(<65 \mu \mathrm{m})$, and also in various physico-chemical parameters (Table 3; Fig. 6). Bospoort Dam showed higher Pt concentrations in the water than Olifantsnek Dam, whereas the sediment demonstrated an opposite pattern. This could be explained by the different sources of Pt in the two impoundments. Olifantsnek Dam is located upstream of the mining activities so that the Pt concentrations are only of geological origin explaining the rather low Pt concentrations in the water and higher concentrations in the sediment. In contrast, Bospoort Dam collects all the runoff and wastewater from the Pt mines explaining the higher Pt concentrations in the water as compared with Olifantsnek Dam. Therefore, as the AMs are only able to take up dissolved metals, higher Pt accumulation in the AMs of Bospoort Dam as compared with Olifantsnek Dam would be expected. However, besides the Pt concentrations in the water phase, other factors such as physico-chemical water parameters (e.g., dissolved organic matter, inorganic ions, salinity, source of $\mathrm{Pt}$ ) can influence the bioavailability of $\mathrm{Pt}[30,31]$. Notable were the chloride concentrations, which were 20 times higher in Bospoort Dam than in Olifantsnek Dam. Chloride is of particular interest as Pt can form chloro-complexes with chloride, which may be not able to cross the polyacrylamide gel layer of the AM.

Another aim of the field study was the comparison of the Pt accumulation in the AM with that of living organisms (Fig. 7). Labuschagne et al. [12] could not detect any Pt in transplanted clams (C. fluminalis africana) exposed at the same sampling sites and during the same sampling period. In contrast to the active monitoring study of Labuschagne et al. [12], in the present study, naturally occurring organisms, i.e., different fish species, were collected at the sampling sites. There are significant differences between the metal uptake mechanisms of AMs and fish. With AMs, biomagnification, the metal fraction that is bioaccumulated via food, is not taken into account. Additionally, AMs are fixed at one point, while fish can move around the impoundment integrating the Pt concentrations over a wider area.

Furthermore, the AMs were deployed in the impoundments for a period of 6 weeks, while the fish had been 
exposed, depending on their age at capture, for a couple of months to a couple of years. These differences in metal uptake routes and exposure period can account for the differences in the Pt bioaccumulation between AM and fish. This may also explain why, in contrast to the AMs, two of the three fish species, i.e., the common carp and sharptooth catfish, showed higher Pt concentrations in the muscle and liver at Bospoort Dam as compared with Olifantsnek Dam and thus the same pattern as the aqueous Pt concentration. These Pt concentrations at Bospoort Dam were significantly higher in the fish tissues as compared with the AMs. The different Pt accumulation patterns of the three fish species and the clam could be explained by differences in their feeding behaviors and preferred habitats, as well as the chemical form in which Pt is present in these systems. Platinum bound to high organic content and suspended solids could be bioavailable to, e.g., filter-feeding organisms, however, not to the AMs as these particles would not be able to diffuse through the gel membranes [31].

Nevertheless, a significant advantage of the AM is that its use is largely standardized, so that many influencing parameters can be excluded. It should be noted that the differences between AMs and other test organisms would also occur if different species of organisms should be used and compared with one another [13]. The present and all previous AM studies (see Table 4), expressed the metal accumulation in the AM as $\mu \mathrm{g} / \mathrm{g}$ related to the $200 \mathrm{mg}$ Chelex-100 beads to enable a comparison with the fish tissues. So far, the mass of Chelex-100 used in the AM is standardized at $200 \mathrm{mg}$. However, as soon as other Chelex-100 masses should be used in the AM metal accumulation values of the AMs given in $\mu \mathrm{g} / \mathrm{g}$ should be handled with care as they are highly dependent on the mass of Chelex-100 beads used in the AM.

In the present study, significant differences between AM and fish were only found at Bospoort Dam demonstrating higher Pt concentrations in muscle and liver of the common carp and liver of the sharptooth catfish, but not for the tissues of the tilapia. This can be explained by the fact that both the common carp and sharptooth catfish are more associated with the sediment and actively feed in and on it [32,33]. In a previous study completed by Erasmus et al. [26], the bioconcentration factors and biota-sediment accumulation factors indicated that both the common carp and sharptooth catfish accumulated Pt more readily from the sediments compared to the dissolved fraction in the water. On the other hand, in another study (unpublished data) the tilapia accumulated Pt concentrations from the dissolved water fraction rather than from the sediments. These three fish species also occupy different trophic levels and utilize different feeding strategies, the common carp and sharptooth catfish are both omnivores, whereas the tilapia is an algaevore and detritivore [32]. Another possible explanation is that common carp and sharptooth catfish specimens were more mature compared to the tilapia specimens, which can attribute to a longer exposure period where the first two species can accumulate higher Pt concentrations compared to the tilapia specimens.

A hyacinth bloom coincided with the AM deployment period in Bospoort Dam. Since the water hyacinth is a floating macrophyte and there is no contact between the roots and sediments, metal uptake can only take place via the water phase. The results showed that Pt was taken up with the highest concentrations in the roots. This supports the laboratory-based findings of Farago and Parsons $[27,28]$, which demonstrate that water hyacinth is an effective bioaccumulator of Pt. It can be assumed that the high biomass of hyacinths (approximately $51 \%$ of the impoundment surface were covered) accumulated metals from the water column to a high degree and thus lowered the exposure concentration and metal accumulation in the AMs. As it was not clear in the present study if the AMs had already reached the accumulation plateau, AMs should be collected in future studies every week (as in the laboratory experiment) to evaluate the uptake kinetics within the AM during the exposure period.

The AM device has successfully been used in many marine and freshwater monitoring studies for a wide range of different metals concurrently with many bioindicator organisms (Table 4). Some of these studies confirmed that the patterns of metal accumulation are similar between the AM and the bioindicators [2, 9, 14], while for several studies different patterns were observed. However, it should be noted that in most studies the test organisms contained higher concentrations than those measured in the AMs. In contrast, Labuschagne et al. [12] found that the AMs accumulated Pt concentrations that could be quantified while the transplanted clams were all below the detection limit.

Additionally, the present laboratory study demonstrated a clear correlation of the Pt concentration in the AM with that in the exposure medium, which has not been shown in other studies for a wide range of concentrations (see references in Table 4). The laboratory uptake experiments revealed that at the lowest exposure concentration $(0.1 \mu \mathrm{g} \mathrm{Pt} / \mathrm{L})$, which was in the upper range of environmentally relevant $\mathrm{Pt}$ concentrations $(\mathrm{pg} / \mathrm{L}$ to ng/L range), the 6-week exposure period was just sufficient to allow for any Pt uptake detection. Further studies should focus on decreasing the AM detection limit by optimizing the surrounding medium of the Chelex-100 beads to increase the Pt accumulation in the AM. Nevertheless, for hot spots like Pt mining areas the AM was successful in indicating environmental exposure. 
However, based on the results of the laboratory exposure study, it is recommended to extend the exposure period to increase the Pt concentration taken up by the AM, as the accumulation plateau was not reached after six weeks.

\section{Conclusions}

So far, the AM has only been validated for $\mathrm{Cu}, \mathrm{Cr}, \mathrm{Pb}$ and $\mathrm{Zn}$ in the marine environment. In the present study, the use of the AM was adapted for the monitoring of Pt under freshwater conditions. Two modifications to the original method are therefore recommended, i.e., washing by centrifugation (it is more practical and less time-consuming) and using a mixture of $\mathrm{HNO}_{3}$ and $\mathrm{HCl}$ for the elution of Pt from the Chelex-100 beads. The field exposures demonstrated that the AM is a promising tool for monitoring Pt in the freshwater environment and the laboratory study demonstrated that it accumulates Pt in a concentration-dependent manner. However, for monitoring of very low Pt concentrations in freshwater environments, the exposure periods should be increased ( $>6$ weeks) and further efforts should be made to improve the accumulation of Pt by the AM and to decrease the detection limit for Pt. The AM can only represent the dissolved bioavailable metal fraction and does not consider, e.g., particlebound metals, which can be taken up by living organisms via the food. Thus, it is recommended to combine active monitoring using living bioindicators with AMs to obtain insight into the role of dissolved bioavailable metal fractions and particulate bound metals in metal exposure in aquatic ecosystems.

\begin{abstract}
Abbreviations
AAS: Atomic absorption spectrometer; Al: Aluminium; AM: Artificial mussel; As: Arsenic; BO: Bioindicator organism; $\mathrm{Cd}$ : Cadmium; $\mathrm{Cl}^{-}$: Chloride; $\mathrm{Co}$ : Cobalt; $\mathrm{Cr}$ : Chromium; Cu: Copper; DO: Dissolved oxygen; EC: Electrical conductivity; Fe: Iron; $\mathrm{HCl}$ : Hydrochloric acid; Hf: Hafnium; Hg: Mercury; $\mathrm{HNO}_{3}$ : Nitric acid; ICPMS: Inductively coupled plasma mass spectrometry; LOD: Limit of detection; Mn: Manganese; $\mathrm{NH}_{4}{ }^{+}$: Ammonium; Ni: Nickel; $\mathrm{NO}_{2}^{-}$: Nitrite; $\mathrm{NO}_{3}^{-}$: Nitrate; $\mathrm{OC}$ : Organic content; $\mathrm{Pb}$ : Lead; $\mathrm{PO}_{4}{ }^{3-}$ : Phosphate; PP: Polypropylene; Pt: Platinum; $\mathrm{SO}_{4}{ }^{2-}$ : Sulfate; SS: Suspended solids; Turb: Turbidity; U: Uranium; Zn: Zinc.
\end{abstract}

\section{Acknowledgements}

This is contribution number 520 of the North-West University (NWU) Water Research Group.

\section{Author contributions}

$\mathrm{ML}$ and JHE contributed towards the conception of study, acquisition, analysis and interpretation of data, and drafting of manuscript. MN contributed with acquisition, analysis and interpretation of data and substantively revised the work. SZ and VW contributed with the conception of the study, acquisition, analysis and interpretation of data and substantively revised the work. NJS and BS contributed to the interpretation of data and substantively revised the work. All authors read and approved the final manuscript.

\section{Funding}

Open Access funding enabled and organized by Projekt DEAL. The financial assistance of the NRF (National Research Foundation, South Africa)
[UID108852] towards this research is hereby acknowledged. This work is based on the research and researchers supported by the National Research Foundation (NRF) of South Africa (NRF Project GERM160623173784; grant 105875; NJ Smit, PI) and BMBF/PT-DLR (Federal Ministry of Education and Research, German, grant 01DG17022; B Sures, PI). Opinions, findings, conclusions and recommendations expressed in this publication are that of the authors, and the NRF and BMBF/PT-DLR accept no liability whatsoever in this regard.

\section{Availability of data and materials}

The datasets used and/or analyzed during the current study are available from the corresponding author on reasonable request.

\section{Ethics approval and consent to participate}

The necessary permits (HO 09/03/17-125 NW; HO 20/02/18-057 NW, North West Province, Department of Rural, Environmental and Agricultural Development) and ethical clearance (NWU-00282-17-A5. NWU-AnimCare) were obtained prior to sampling.

\section{Consent for publication}

Not applicable.

\section{Competing interests}

The authors declare that they have no competing interests.

\section{Author details}

${ }^{1}$ Water Research Group, Unit for Environmental Sciences and Management, North-West University, Potchefstroom 2520, South Africa. ${ }^{2}$ Department of Aquatic Ecology and Centre for Water and Environmental Research, University of Duisburg-Essen, 45141 Essen, Germany.

Received: 19 November 2020 Accepted: 23 January 2021

Published online: 10 February 2021

\section{References}

1. Goldberg ED (1975) The mussel watch: a first step in global marine monitoring. Mar Pollut Bull 6:111-114. https://doi.org/10.1016/0025326X(75)90271-4

2. Wu RSS, Lau TC, Fung WKM, Ko PH, Leung KMY (2007) An 'artificial mussel' for monitoring heavy metals in marine environments. Environ Pollut 145(1):104-110. https://doi.org/10.1016/j.envpol.2006.03.053

3. Leung KMY, Furness RW, Svavarsson J, Lau TC, Wu RSS (2008) Field validation, in Scotland and Iceland, of the artificial mussel for monitoring trace metals in temperate seas. Mar Pollut Bull 57(6):790-800. https://doi. org/10.1016/..marpolbul.2008.01.033

4. Wu R, Lau T (1996) Polymer-ligands: a novel chemical device for monitoring heavy metals in the aquatic environment? Mar Pollut Bull 32(5):391396. https://doi.org/10.1016/0025-326X(95)00154-F

5. Vrana B, Allan IJ, Greenwood R, Mills GA, Dominiak E, Svensson K, Knutsson J, Morrison G (2005) Passive sampling techniques for monitoring pollutants in water. Trends Anal Chem 24(10):845-868. https://doi. org/10.1016/j.trac.2005.06.006

6. Claassens L, Dahms S, Van Vuren J, Greenfield R (2016) Artificial mussels as indicators of metal pollution in freshwater systems: a field evaluation in the Koekemoer Spruit, South Africa. Ecol Ind 60:940-946. https://doi. org/10.1016/j.ecolind.2015.08.047

7. Russell WMS, Burch RL (1959) The principles of humane experimental technique. Methuen, London. https://doi.org/10.5694/j.1326-5377.1960. tb73127.x

8. Kibria G, Lau T, Wu R (2012) Innovative 'Artificial Mussels' technology for assessing spatial and temporal distribution of metals in Goulburn-Murray catchments waterways, Victoria, Australia: effects of climate variability (dry vs. wet years). Environ Int 50:38-46. https://doi.org/10.1016/j.envin t.2012.09.006

9. Degger N, Chiu JMY, Po BHK, Tse ACK, Zheng GJ, Zhao D-M, Xu D, Cheng Y-S, Wang X-H, Liu W-H, Lau TC, Wu RSS (2016) Heavy metal contamination along the China coastline: a comprehensive study using Artificial Mussels and native mussels. Environ Manage 180:238-246. https://doi. org/10.1016/j.marpolbul.2011.04.040 
10. Dahms-Verster S, Baker N, Greenfield R (2018) A multivariate examination of 'artificial mussels' in conjunction with spot water tests in freshwater ecosystems. Environ Monit Assess 190(7):427. https://doi.org/10.1007/ s10661-018-6764-6

11. Genç TO, Po BH, Yılmaz F, Lau T-C, Wu RS, Chiu JM (2018) Differences in metal profiles revealed by native mussels and artificial mussels in Sarıçay Stream, Turkey: implications for pollution monitoring. Mar Freshw Res 69(9):1372-1378. https://doi.org/10.1071/MF17293

12. Labuschagne M, Wepener V, Nachev M, Zimmermann S, Sures B, Smit NJ (2020) The application of artificial mussels in conjunction with transplanted bivalves to assess elemental exposure in a platinum mining area. Water 12(1):32. https://doi.org/10.3390/w12010032

13. Degger N, Wepener V, Richardson BJ, Wu RSS (2011) Application of artificial mussels (AMs) under South African marine conditions: a validation study. Mar Pollut Bull 63(5):108-118. https://doi.org/10.1016/j.marpo lbul.2011.04.040

14. Gonzalez-Rey M, Lau T, Gomes T, Maria V, Bebianno M, Wu R (2011) Comparison of metal accumulation between 'Artificial Mussel' and natural mussels (Mytilus galloprovincialis) in marine environments. Mar Pollut Bull 63(5):149-153. https://doi.org/10.1016/j.marpolbul.2010.12.007

15. Kibria G, Hossain MM, Mallick D, Lau T, Wu R (2016) Monitoring of metal pollution in waterways across Bangladesh and ecological and public health implications of pollution. Chemosphere 165:1-9. https://doi. org/10.1016/j.chemosphere.2016.08.1210045-6535/

16. Kibria G, Hossain MM, Mallick D, Lau T, Wu R (2016) Trace/heavy metal pollution monitoring in estuary and coastal area of Bay of Bengal, Bangladesh and implicated impacts. Mar Pollut Bull 105(1):393-402. https://doi. org/10.1016/j.marpolbul.2016.02.021

17. Ruiz-Fernández AC, Wu RS, Lau T-C, Pérez-Bernal LH, Sánchez-Cabeza JA, Chiu JM (2018) A comparative study on metal contamination in Estero de Urias lagoon, Gulf of California, using oysters, mussels and artificial mussels: implications on pollution monitoring and public health risk. Environ Pollut 243:197-205. https://doi.org/10.1016/j.envpol.2018.08.047

18. Shen H, Kibria G, Wu RS, Morrison P, Nugegoda D (2020) Spatial and temporal variations of trace metal body burdens of live mussels Mytilus galloprovincialis and field validation of the Artificial Mussels in Australian inshore marine environment. Chemosphere 248:126004. https://doi. org/10.1016/j.chemosphere.2020.126004

19. Hoppstock K, Sures B (2004) Platinum-group metals. In: Merian E, Anke M, Ihnat M, Stoeppler M (eds) Elements and their compounds in the environment: occurrence, analysis and biological relevance, 2 nd edn. Wiley, KGaA, Weinheim, pp 1047-1086

20. Ruchter N, Zimmermann S, Sures B (2015) Field studies on PGE in aquatic ecosystems. In: Zereini F, Wiseman CLS (eds) Platinum metals in the environment. Springer, Heidelberg, pp 351-360. https://doi.org/10.1007/9783-662-44559-4_22

21. Sures $B$, Ruchter $N$, Zimmermann S (2015) Biological effects of PGE on aquatic organisms. In: Zereini F, Wiseman CLS (eds) Platinum metals in the environment. Springer, Heidelberg, pp 383-399. https://doi. org/10.1007/978-3-662-44559-4_24

22. Brand SJ, Erasmus JH, Labuschagne M, Grabner D, Nachev M, Zimmermann S, Wepener V, Smit N, Sures B (2019) Bioaccumulation and metal-associated biomarker responses in a freshwater mussel, Dreissena polymorpha, following short-term platinum exposure. Environ Pollut 246:69-78. https://doi.org/10.1016/j.envpol.2018.11.061

23. Johnson-Matthey (2019) PGM market report May 2019. London

24. Erasmus JH, Malherbe W, Zimmermann S, Lorenz AW, Nachev M, Wepener V, Sures B, Smit NJ (2020) Metal accumulation in riverine macroinvertebrates from a platinum mining region. Sci Total Environ. https:// doi.org/10.1016/j.scitotenv.2019.134738

25. Almécija C, Cobelo-García A, Wepener V, Prego R (2017) Platinum group elements in stream sediments of mining zones: the Hex River (Bushveld Igneous Complex, South Africa). Afr Earth Sci 129:934-943. https://doi. org/10.1016/j.jafrearsci.2017.02.002

26. Erasmus JH, Wepener V, Nachev M, Zimmermann S, Malherbe W, Sures B, Smit NJ (2020) The role of fish helminth parasites in monitoring metal pollution in aquatic ecosystems: a case study in the world's most productive platinum mining region. Parasitol Res. https://doi.org/10.1007/s0043 6-020-06813-1

27. Farago ME, Parsons PJ (1983) The uptake and accumulation of platinum metals by the water hyacinth (Eichhornia crassipes). Inorg Chim Acta 79:233-234. https://doi.org/10.1016/S0020-1693(00)95274-5

28. Farago M, Parsons P (1994) The effects of various platinum metal species on the water plant Eichhornia crassipes. Chem Speciat Bioavailab 6(1):1-12. https://doi.org/10.1080/09542299.1994.11083218

29. Samczyński Z, Danko B, Dybczyński R (2000) Application of Chelex 100 ion exchange resin for separation and determination of palladium, platinum and gold in geological and industrial materials by neutron activation analysis. Chem Anal (Warsaw) 45(6):843-857

30. Zimmermann S, Sures B, Ruchter N (2015) Laboratory studies on the uptake and bioaccumulation of PGE by aquatic plants and animals. In: Zereini F, Wiseman CLS (eds) Platinum metals in the environment. Springer, Heidelberg, pp 361-381. https://doi.org/10.1007/978-3-66244559-4_23

31. Abdulbur-Alfakhoury E, Van Zutphen S, Leermakers M (2019) Development of the diffusive gradients in thin films technique (DGT) for platinum (Pt), palladium (Pd), and rhodium (Rh) in natural waters. Talanta 203:34-48. https://doi.org/10.1016/j.talanta.2019.05.038

32. Skelton $P(2001) A$ complete guide to the freshwater fishes of southern Africa. Struik, Cape Town, South Africa

33. Pheiffer W, Wolmarans NJ, Gerber R, Yohannes YB, Ikenaka Y, Ishizuka M, Smit NJ, Wepener V, Pieters R (2018) Fish consumption from urban impoundments: What are the health risks associated with DDTs and other organochlorine pesticides in fish to township residents of a major inland city. Sci Total Environ 628:517-527. https://doi.org/10.1016/j.scito tenv.2018.02.075

\section{Publisher's Note}

Springer Nature remains neutral with regard to jurisdictional claims in published maps and institutional affiliations.

\section{Submit your manuscript to a SpringerOpen ${ }^{\circ}$ journal and benefit from:}

- Convenient online submission

- Rigorous peer review

- Open access: articles freely available online

- High visibility within the field

Retaining the copyright to your article

Submit your next manuscript at $\boldsymbol{\text { springeropen.com }}$ 